\title{
Intrinsic Functional Connectivity in the Adult Brain and Success in Second-Language Learning
}

\author{
Xiaoqian J. Chai, ${ }^{1}$ Jonathan A. Berken, ${ }^{1,3}$ Elise B. Barbeau, ${ }^{1}$ Jennika Soles, ${ }^{1}$ Megan Callahan, ${ }^{1}$ Jen-Kai Chen, ${ }^{1}$ \\ and Denise Klein ${ }^{1,2,3}$ \\ ${ }^{1}$ Cognitive Neuroscience Unit, Montreal Neurological Institute, ${ }^{2}$ Department of Neurology and Neurosurgery, and ${ }^{3}$ Centre for Research on Brain, Language, \\ and Music, McGill University, Montreal, Quebec H3A 0G4, Canada
}

There is considerable variability in an individual's ability to acquire a second language (L2) during adulthood. Using resting-state fMRI data acquired before training in English speakers who underwent a 12 week intensive French immersion training course, we investigated whether individual differences in intrinsic resting-state functional connectivity relate to a person's ability to acquire an L2. We focused on two key aspects of language processing — lexical retrieval in spontaneous speech and reading speed—and computed whole-brain functional connectivity from two regions of interest in the language network, namely the left anterior insula/frontal operculum (AI/FO) and the visual word form area (VWFA). Connectivity between the left AI/FO and left posterior superior temporal gyrus (STG) and between the left AI/FO and dorsal anterior cingulate cortex correlated positively with improvement in L2 lexical retrieval in spontaneous speech. Connectivity between the VWFA and left mid-STG correlated positively with improvement in L2 reading speed. These findings are consistent with the different language functions subserved by subcomponents of the language network and suggest that the human capacity to learn an L2 can be predicted by an individual's intrinsic functional connectivity within the language network.

Key words: individual differences; insula; language; learning; resting-state fMRI; VWFA

Significance Statement

There is considerable variability in second-language learning abilities during adulthood. We investigated whether individual differences in intrinsic functional connectivity in the adult brain relate to success in second-language learning, using resting-state functional magnetic resonance imaging in English speakers who underwent a 12 week intensive French immersion training course. We found that pretraining functional connectivity within two different language subnetworks correlated strongly with learning outcome in two different language skills: lexical retrieval in spontaneous speech and reading speed. Our results suggest that the human capacity to learn a second language can be predicted by an individual's intrinsic functional connectivity within the language network.

\section{Introduction}

Language processing is supported by a widely distributed brain network anchored by core regions in the left inferior frontal gyrus (IFG) and left superior temporal gyrus (STG; Price, 2012). The language network identified by resting-state functional connectivity shows highly reproducible patterns that are consistent with those reported in task-based brain imaging studies (Tomasi and

\footnotetext{
Received June 10, 2015; revised Nov. 18, 2015; accepted Nov. 27, 2015.

Author contributions: J.A.B., J.S., J.-K.C., and D.K. designed research; X.J.C., J.A.B., J.S., and J.-K.C. performed research; X.J.C., E.B.B., and M.C. analyzed data; X.J.C., J.A.B., and D.K. wrote the paper.

This study was funded by support from the Blema and Arnold Steinberg Family Foundation and Natural Sciences and Engineering Research Council of Canada.

The authors declare no competing financial interests.

Correspondence should be addressed to Dr. Xiaogian J. Chai, Montreal Neurological Institute, McGill University, Montreal, QC H3A 2B4, Canada. E-mail: jenny.chai@gmail.com.

DOI:10.1523/JNEUROSCI.2234-15.2016

Copyright $\odot 2016$ the authors $\quad 0270-6474 / 16 / 360755-07 \$ 15.00 / 0$
}

Volkow, 2012). Resting-state connectivity has been correlated with individual differences in behavior (Fox et al., 2007; Baldassarre et al., 2012) and is thought to reflect intrinsic functional organization of the brain (Fox and Raichle, 2007). Previous work has linked variability in resting-state connectivity within the language network with specific language abilities, such as semantic processing (Wei et al., 2012) and reading competency (Koyama et al., 2011).

There is considerable variability in an individual's ability to acquire a second language (L2) during adulthood (Golestani and Zatorre, 2009). Individual differences in resting-state connectivity have been associated with language learning abilities. Individuals with stronger left insula/frontal operculum (AI/FO)-superior parietal resting-state connectivity have been shown to perform better when learning Hindi dental-retroflex sounds (Ventura-Campos et al., 2013), and resting-state connectivity of the left insula has also been associated with better L2 
word learning (Veroude et al., 2010). The aim of the present study was to investigate the relationship between pretraining resting-state connectivity in the brain and improvement in L2 performance in adult English speakers after 12 weeks of intensive French immersion training. Given that language learning relates to improved conversational fluency and reading proficiency, we used speech samples (spontaneous speech and paragraph reading) to measure improvement in L2 learning, an approach that looks at language learning in a naturalistic and ecologically valid way (Kircher et al. 2000).

We focused on two central aspects of language processinglexical retrieval and reading speed-that are supported by common and independent cognitive processes. Many people speak well, even multiple languages, without necessarily being competent readers, and individuals can read well without necessarily being articulate in a language (Lewis and Freebairn, 1992; Bird et al., 1995). Evidence from both lesion and neuroimaging studies suggest that lexical retrieval and reading are mediated by overlapping but distinct neural substrates (Dehaene and Cohen, 2011; Price, 2012). Lexical retrieval is primarily mediated by the left frontal regions (Milner, 1964; Price, 2012). In particular, the left IFG (including AI/FO) has been linked consistently to lexical/ semantic retrieval and verbal fluency (Damasio et al., 2004; Baldo et al., 2006), and lesions to this region result in expressive aphasia (Nestor et al., 2003). In relation to L2 learning, the left AI/FO has been implicated in lexical search and retrieval (Klein et al., 1995; Perani et al., 2003), and its role as a marker of L2 attainment associated with higher L2 proficiency has been emphasized (Chee et al. 2004).

Although overt reading also involves recruitment of the left frontal region, reading recruits brain regions specifically involved in mapping the written form of language into phonological representations. Such grapheme to phoneme transformations engage the left ventral temporo-occipital cortex, known as the visual word form area (VWFA; McCandliss et al., 2003; Dehaene and Cohen, 2011). The VWFA is activated consistently during reading across different languages (Nakamura et al., 2012), and lesions near this region lead to slower reading speed (Gaillard et al., 2006). Functional connectivity between visual orthographic processing and other language regions has been associated with reading abilities, suggesting that the coordination of brain regions supporting visual and phonological processing is crucial for successful reading in both L1 and L2 (Zhang et al., 2014).

In the present study, we investigated the relationship between individual variation in resting-state connectivity and L2 learning performance. Based on previous findings, we focused on two regions of interest (ROIs): (1) the left AI/FO; and (2) the VWFA. Here we show that prelearning functional connectivity of the left $\mathrm{AI} / \mathrm{FO}$ and VWFA relates to L2 learning performance in lexical retrieval in spontaneous speech and reading speed, respectively.

\section{Materials and Methods}

Participants. Fifteen English speakers (mean \pm SD age, $24.9 \pm 3.7$ years; 10 females) were recruited from a 12 week intensive French training course at McGill University. Eligible participants were right-handed and had normal or corrected-to-normal visual acuity. Exclusion criteria included hearing or reading impairment, history of a traumatic brain injury or neurological disorder, or conditions incompatible with MRI (e.g., metal implants, braces, electronically, magnetically, or mechanically activated devices such as cochlear implants, or claustrophobia). Individuals with a high degree of musical skill were excluded, given the link between musical training and language ability (Schön et al., 2004) and the demonstrated plastic effects of musical experience on brain organization (Gaser and Schlaug, 2003). The participants were students from outside of Quebec (nine from other provinces of Canada, two from the United States, three from the United Kingdom, and one from Australia) who had some exposure to French since arriving in Quebec but considered themselves solely speakers of English. All of them attended English schools growing up and went to English universities. Students who spoke a language other than English were excluded. The study was approved by the Research Ethics Board of the Montreal Neurological Institute (MNI), and participants gave written informed consent.

French training course. Participants completed a 12 week French intensive training course $(6 \mathrm{~h} / \mathrm{d}, 5 \mathrm{~d} /$ week $)$ that was part of the "Certificate of Proficiency in French-Language and Culture" program offered by the School of Continuing Studies at McGill University, aimed at developing competence handling complex communicative exchanges and developing competence in reading. Compared with some of the previous studies related to L2 learning (Veroude et al., 2010; Ventura-Campos et al., 2013), the L2 training in the present study was more intensive, used a real-world type of design, and was done in a more immersive setting in which a large part of learning was achieved through conversations and learning from context (combination of classroom instruction in French, conversation partners, and frequent cultural activities and interaction with native speakers). Such a naturalistic approach to L2 learning is thought to lead to better learning outcomes (Dahl and Vulchanova, 2014).

Assessment of language proficiency before and after training. Participants were assessed for their language proficiency in English (L1) and French (L2) before (Time 1) and after (Time 2) the training course. Participants completed a subjective Language Experience and Proficiency Questionnaire (LEAP-Q; Marian et al., 2007), which provided detailed information about language acquisition history background. Language abilities were assessed quantitatively using spontaneous speech samples generated by subjects in both English and French and standardized paragraphs that were read aloud in French and English. French and English speech samples from the participants were rated by native French and native English speakers, respectively.

We have used spontaneous speech and passage reading tasks in a recent study to assess L2 proficiency in a group of English-French bilinguals and related such behavioral measures to neuroimaging data in the same subjects during the performance of an overt reading task (Berken et al., 2015). In the present study, we used speech samples (spontaneous speech and passage reading) to measure improvement in L2 learning because, in previous studies, we found poor correlation between scores obtained on standardized tests, such as the Peabody Picture Vocabulary Test (Dunn and Dunn, 1997), and the ability to converse proficiently in a language. Given the global nature of the language training in this course and the global nature of language improvement, spontaneous speech samples provide a more naturalistic and ecologically valid way of assessing language improvement compared with standardized tests, which usually involve single-word processing. Spontaneous speech tasks such as the one used in the present study have been used previously to study the neural correlates of lexical retrieval in spontaneous speech (Kircher et al., 2000; Troiani et al., 2008). Kircher et al. (2000) investigated lexical retrieval during fluent speech production by asking participants to describe Rorschach inkblots for $3 \mathrm{~min}$ and related the number of words produced with brain activations. In the neuropsychology and neuroimaging literature (Thurstone and Thurstone, 1943; Milner, 1964; Benton, 1968), there is a long history of using the number of words produced within a limited time period that fit a certain criteria as an index for verbal fluency and integrity of function of the left frontal cortex. Here we extend this approach to measure lexical retrieval success during spontaneous speech generation in an L2.

In the present study, participants were instructed to speak for $2 \mathrm{~min}$ in each language and were asked to describe, for example, a typical day at the [beach/zoo]. They were encouraged to use relevant vocabulary to create stories that fit the prompt. Instructions were delivered in the language required for the response. We calculated the total number of words correctly produced in the spontaneous speech sample as an index of lexical retrieval success. Errors (grammar, gender, misused words) were excluded.

To assess reading skill improvement, we adapted a measure (words per minute) that has been used previously to relate brain measures to reading 
abilities (Dehaene et al., 2010; Thiebaut de Schotten et al., 2014; Zhang et al., 2014). Dehaene et al. (2010) showed that activations in the VWFA were correlated positively with words read per minute in word and sentence reading. Here we used whole-paragraph reading instead of singleword reading to represent reading under more natural conditions. Participants were instructed to read aloud English and French passages that were selected from a bank of short texts used extensively for neuropsychological testing at the MNI and that were matched for word count and contained all of the phonemes of the respective language. The number of words read per minute was calculated from the reading speech samples and used as an index of reading ability, similar to what was done in the study by Dehaene et al. (2010).

Imaging procedure. Data were acquired on a $3 \mathrm{~T}$ TrioTim Siemens scanner using a 32-channel head coil. All participants underwent a resting fMRI scan before the language-learning course. Subjects were instructed to relax and fixate on a cross on the screen. Resting scan images were obtained in 42 3.5-mm-thick transverse slices, covering the entire brain (TR, $2210 \mathrm{~ms}$; TE, $30 \mathrm{~ms}$; matrix size, $64 \times 64$; FOV, $224 \mathrm{~mm}$; flip angle $90^{\circ}$ ). One hundred thirty-six volumes were obtained in $5 \mathrm{~min} 9 \mathrm{~s}$. For all subjects, high-resolution $\mathrm{T}_{1}$-weighted images obtained from a $3 \mathrm{D}$ magnetization prepared rapid gradient echo sequence were used as anatomical references (TR, $23 \mathrm{~ms}$; TE, $2.98 \mathrm{~ms}$; slice thickness, $1 \mathrm{~mm}$; image matrix, $256 \times 256$; flip angle, $30^{\circ}$; FOV $256 \mathrm{~mm}$; interleaved excitation).

Functional connectivity analysis. Resting-state fMRI data were first preprocessed in SPM8 (Wellcome Department of Imaging Neuroscience, London, UK), using standard spatial preprocessing steps. Images were slice-time corrected, realigned and resliced, normalized in MNI space, and smoothed with a $6 \mathrm{~mm}$ kernel. Functional connectivity analysis was performed using a seed-driven approach with the in-house, custom software CONN (Chai et al., 2012; Whitfield-Gabrieli and Nieto-Castanon, 2012). We performed seed-voxel correlations by estimating temporal correlations between the blood oxygen level-dependent (BOLD) signal from our a priori ROIs (seeds) and BOLD signal at every brain voxel. We performed resting-state connectivity analysis from two seed regions based on coordinates from the literature: the left AI/FO (-28, 19, 2; Chee et al., 2004) and the left VWFA ( $-44,-50,-20$; McCandliss et al., 2003), defined as $6 \mathrm{~mm}$ spheres. These two seeds were chosen related to their links with lexical retrieval/verbal fluency and reading, respectively.

Physiological and other spurious sources of noise were estimated and regressed out using the anatomical CompCor method (aCompCor; Behzadi et al., 2007). The anatomical image for each participant was segmented into white matter (WM), gray matter, and CSF masks using SPM8. To minimize partial voluming with gray matter, the WM and CSF masks were eroded by one voxel, which resulted in substantially smaller masks than the original segmentations (Chai et al., 2012). The eroded WM and CSF masks were then used as noise ROIs. Based on previous results (Chai et al., 2012), five principal components of the signals from $\mathrm{WM}$ and CSF noise ROIs were removed with regression. A temporal bandpass filter of $0.008-0.083 \mathrm{~Hz}$ was applied to the time series. Residual head motion parameters (three rotation and three translation parameters, plus another six parameters representing their first-order temporal derivatives) were regressed out. Artifact/outlier scans were also regressed out. Outlier time points during the scan were identified using ART (Artifact Detection Tools). Specifically, an image was defined as an outlier (artifact) image if the average intensity deviated $>3$ SDs from the mean intensity in the session or composite head movement exceeded $1 \mathrm{~mm}$ from the previous image. The composite head movement was computed by first converting six rotation/translation head motion parameters into another set of six parameters characterizing the trajectories of six points located on the center of each of the faces of a bounding box around the brain. The maximum scan-to-scan movement of any of these points was then computed as the single composite movement measure. Each outlier scan was represented by a single regressor in the general linear model (GLM), with a 1 for the outlier time point and $0 \mathrm{~s}$ elsewhere.

First-level correlation maps were produced by extracting the residual BOLD time course from each seed and computing Pearson's correlation coefficients between that time course and the time course of all other voxels. Correlation coefficients were converted to normally distributed $z$ scores using the Fisher's transformation to allow for second-level GLM
Table 1. Mean \pm SD of the number of unique words produced correctly during spontaneous speech (lexical retrieval), words per minute (paragraph reading speed), and self-report rating for speaking and reading proficiency from LEAP-0 (scale of 1-10) before (Time 1) and after (Time 2) learning

\begin{tabular}{lccccc}
\hline & French (L2) & & & English (L1) \\
\cline { 2 - 3 } & Time 1 & \multicolumn{1}{c}{ Time 2 } & & Time 1 & \multicolumn{1}{c}{ Time 2 } \\
\hline Lexical retrieval & $10.8 \pm 8.6$ & $25.7 \pm 7.1^{*}$ & & $64.0 \pm 17.2$ & $66.1 \pm 15.1$ \\
Reading speed & $79.4 \pm 15.4$ & $100.8 \pm 15.3^{*}$ & & $177.4 \pm 22.5$ & $189.3 \pm 20.9$ \\
LEAP-Q Speaking & $1.7 \pm 0.7$ & $3.13 \pm 0.8^{*}$ & & $9.7 \pm 0.5$ & $9.6 \pm 0.5$ \\
LEAP-Q reading & $2.6 \pm 1.3$ & $5.0 \pm 1.73^{*}$ & & $9.7 \pm 0.5$ & $9.5 \pm 0.7$ \\
\hline
\end{tabular}

* Time $2>$ Time $1, p<0.001$.

analyses. First-level connectivity maps for each participant and L2 learning outcome (Time 2 - Time 1; improvement in lexical retrieval in spontaneous speech for the AI/FO seed; improvement in reading speed for the VWFA seed) were entered into whole-brain regression analyses to determine brain regions that showed a significant relationship between resting-state connectivity strength and L2 learning outcome. In a subsidiary analysis, age and gender of the participants were included as nuisance regressors in the model to account for the effects of these factors. All reported clusters survived the threshold of $p<0.05$, corrected using a familywise error correction for multiple comparisons implemented in SPM8, with a voxel-level significance of $p<0.005$.

\section{Results}

\section{Behavioral results}

Self-reported proficiency in reading and speaking (LEAP-Q) increased from Time 1 to Time 2 in French ( $p$ values $<0.001)$ but not in English ( $p$ values $>0.4$; Table 1 ). In the L2 (French), on the spontaneous speech samples, compared with Time 1, participants improved significantly at Time 2 in lexical retrieval (i.e., number of unique words produced correctly, $t_{(14)}=8.3, p<$ $0.001)$. In L2 (French), on the passage reading, compared with Time 1, participants showed an increase at Time 2 in reading speed $\left(t_{(14)}=7.01, p<0.001\right)$. Across participants, there was no correlation between improvement in lexical retrieval and reading speed $(p=0.2)$. In the L1 English, lexical retrieval success in spontaneous speech and paragraph reading speed did not differ at Time 1 and Time 2 ( $p$ values $>0.1$ ).

\section{Left AI/FO connectivity and improvement in lexical retrieval during spontaneous speech}

Functional connectivity between the left AI/FO and a cluster in the left posterior STG (pSTG) and between left AI/FO and the dorsal anterior cingulate cortex (ACC) correlated with improvement in lexical retrieval (Time 2 - Time 1) while producing spontaneous speech in the L2, French (Fig. 1; Table 2, top). Individuals with stronger connectivity between these regions showed greater improvement in the number of unique words produced during L2 spontaneous speech after learning. AI/FO connectivity did not correlate with improvement in reading speed in French. These clusters remained significant when age and gender were included in the GLM as nuisance regressors.

\section{VWFA connectivity and improvement in reading speed}

Functional connectivity between the VWFA seed and a cluster in the left mid-STG was correlated significantly with improvement in French paragraph reading speed (Time 2 - Time 1; Fig. 2; Table 2, bottom). Individuals with stronger connectivity between these two regions showed greater improvement in French reading speed (words read per minute) after intensive language training. VWFA connectivity did not correlate with French lexical retrieval improvement as elicited during spontaneous speech. 
A

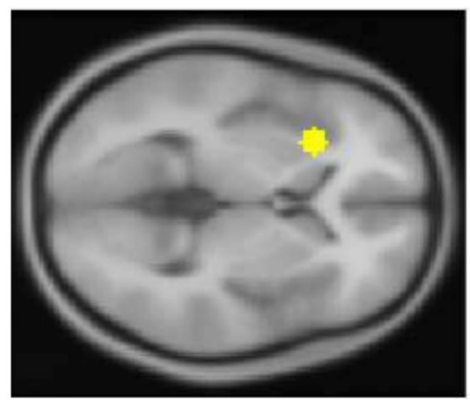

B

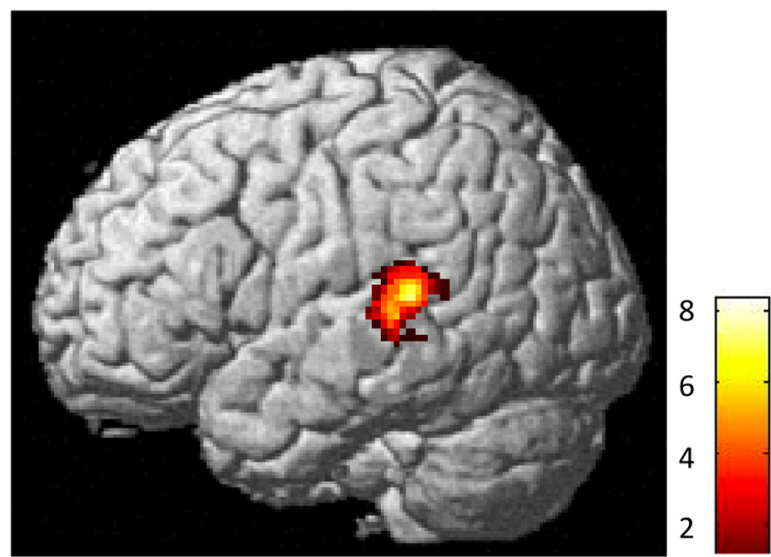

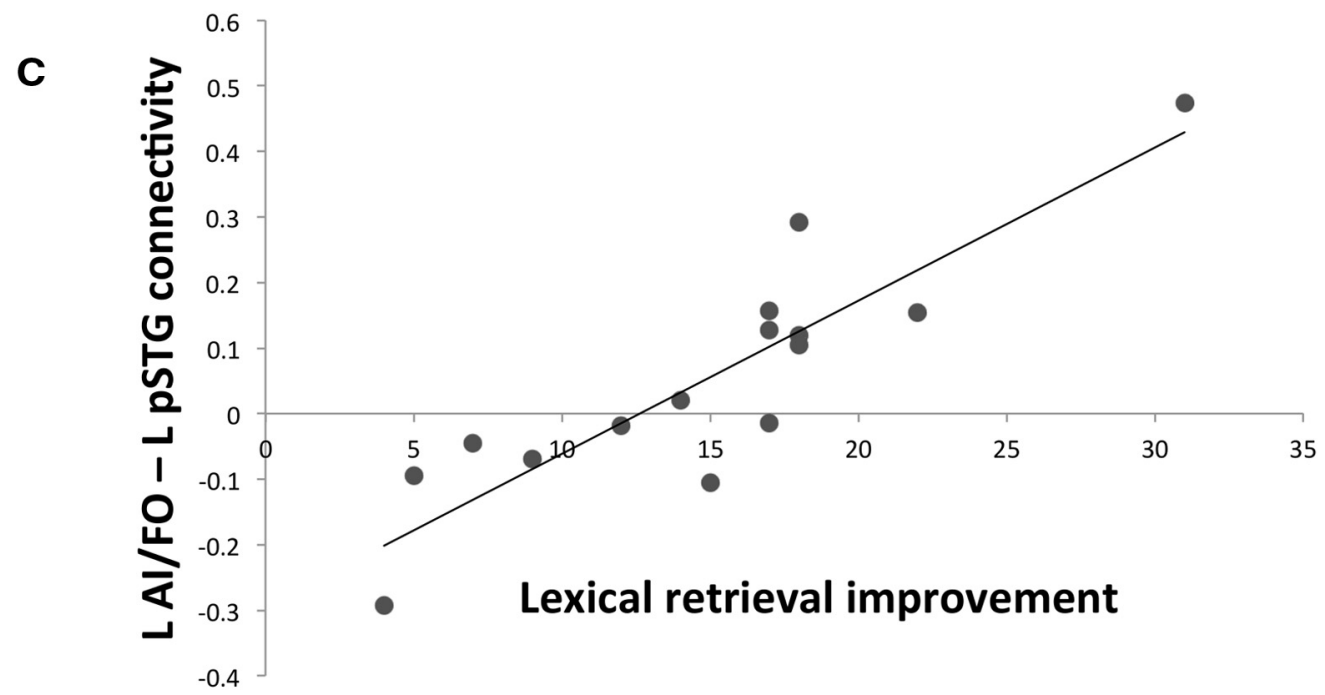

Figure 1. Resting-state connectivity between the left AI/F0 and left pSTG correlated with improvement in lexical retrieval during spontaneous speech. $A$, Location of the left Al/F0 seed. $\boldsymbol{B}$, The left pSTG cluster showed a significant relationship between connectivity strength and improvement in lexical retrieval during spontaneous speech. C, Left Al/F0-pSTG functional connectivity (Fisher'sz) plotted against improvement in lexical retrieval during spontaneous speech.

Table 2. Resting-state functional connectivity correlated with performance in French (L2) learning

\begin{tabular}{lcccc}
\hline & \multicolumn{3}{l}{ Correlation with L2 learning outcome } \\
\cline { 2 - 5 } & BA & $x, y, z$ & $z$ & $k$ \\
\hline Left AI/F0 seed (correlation with lexical retrieval) & & & & \\
$\quad$ Left STG & 22 & $-68,-36,10$ & 4.82 & 302 \\
$\quad$ Dorsal ACC & 24 & $0,26,24$ & 4.49 & 497 \\
VWFA seed (correlation with reading speed) & & & & \\
$\quad$ Left STG & 22 & $-50,-22,4$ & 4.05 & 187 \\
\hline
\end{tabular}

Top, Connectivity of the left Al/F0 correlated with improvement in lexical retrieval during spontaneous speech (number of unique words correctly produced). Bottom, Connectivity of the VWFA correlated with improvement in reading speed (words per minute). Peak coordinates ( $x y z)$ were based on MNI space. BA, Brodmann area; $k$, cluster size (number of voxels).

This result remained significant when age and gender were included in the GLM as nuisance regressors.

\section{Discussion}

We examined the relationship between individual differences in intrinsic functional connectivity and L2 learning abilities. Prelearning resting-state connectivity between left $\mathrm{AI} / \mathrm{FO}$ and left pSTG and between left AI/FO and dorsal ACC correlated with improvement in L2 lexical retrieval. Prelearning resting-state connectivity between the left VWFA and left mid-STG correlated with improvement in L2 reading speed. These results demon- strate that intrinsic functional connectivity can be related to individual variability in L2 learning abilities in spontaneous lexical retrieval and reading, two domains of language learning that are subserved by overlapping and distinct neural pathways.

The relationship between left AI/FO connectivity and L2 lexical retrieval improvement is consistent with the role of this region in language processing and in L2 acquisition (Ardila et al., 2014). The left IFG (including AI/FO) is involved in selection and integration of semantic information (Homae et al., 2002), and is linked consistently to lexical retrieval and verbal fluency (Wagner et al., 2001; Damasio et al., 2004; Baldo et al., 2006; Hirshorn and Thompson-Schill, 2006; Grogan et al., 2012). Using lesion and PET data, Damasio et al. (2004) reported left frontal operculum involvement in semantic retrieval. Grogan et al. (2012) showed that gray matter density of the left IFG correlated positively with L2 lexical efficiency, measured by the number of words produced in a timed verbal fluency task, and a recent study found verbal fluency performance correlated with increased cortical thickness in the left insula (Roehrich-Gascon et al., 2015). In relation to L2 acquisition, increased activity in the left AI/FO has been associated with L2 word learning (Raboyeau et al., 2004) and verbal fluency (Perani et al., 2003). Perani et al. (2003) found higher activations for L2 compared with L1 in left AI/FO during verbal fluency in highly proficient bilinguals. Chee et al. (2004) found greater left $\mathrm{AI} / \mathrm{FO}$ activations in a phonological working memory 
A

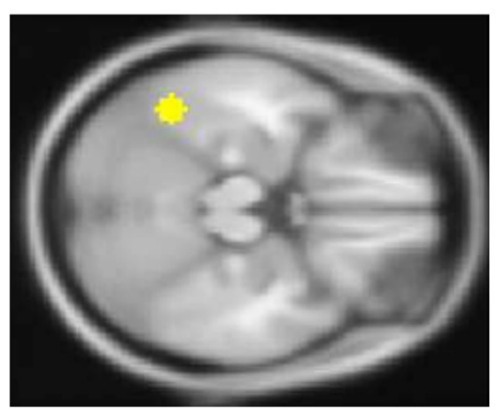

B

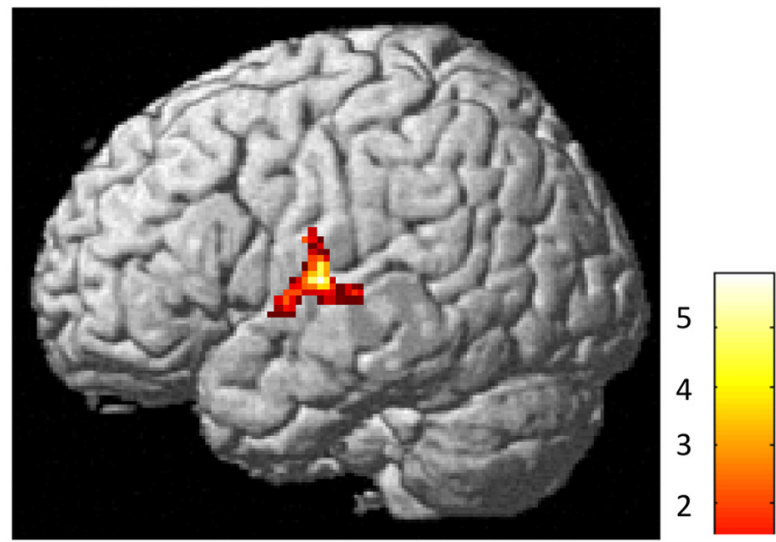

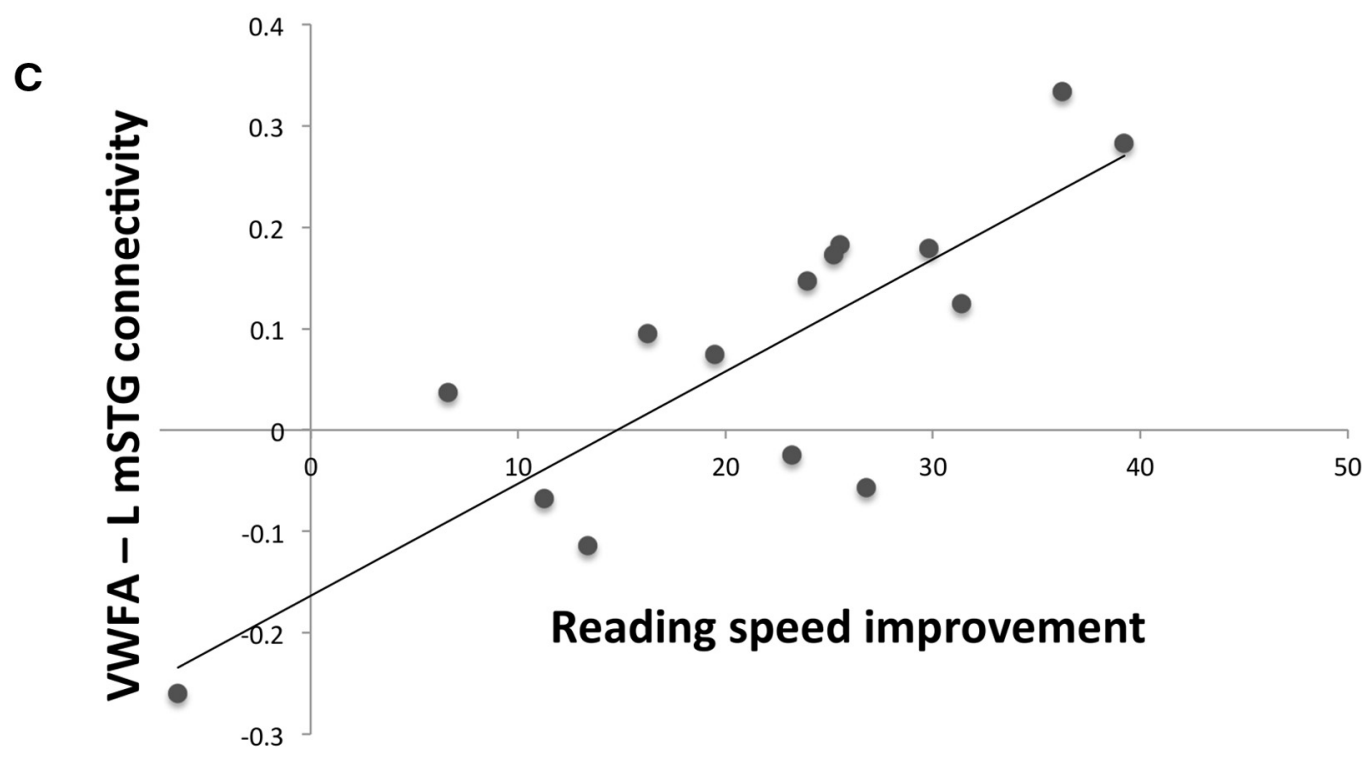

Figure 2. Resting-state connectivity between the VWFA and left mid-STG correlated with improvement in reading speed. $\boldsymbol{A}$, Location of the VWFA seed. $\boldsymbol{B}$, The left mid-STG cluster showed a significant relationship between connectivity strength and improvement in reading speed. C, VWFA-mid STG functional connectivity (Fisher's $z$ ) plotted against improvement in reading speed.

task in highly proficient compared with less proficient bilinguals and suggested that this region is a marker of language attainment.

The correlation between AI/FO connectivity and lexical fluency found in the present study may reflect the role of the left IFG in lexical retrieval and on some level in phonological processing. Using a verbal fluency task combined with voxel- and ROI-based lesion-symptom mapping, Biesbroek et al. (2015) showed that anatomical correlates of semantic and phonemic fluency overlap in the left IFG and insula. Lexical access also interacts with phonological planning during speaking (Goldrick and Blumstein, 2006; Heisler et al., 2010). It is thus possible that the left IFG supports both semantic retrieval and phonological processing, which contribute to successful verbal fluency.

The integrity of the circuitry connecting the left IFG and left posterior language regions has been suggested to be important for L2 learning. Anatomical connectivity in a left-hemisphere network consisting of the IFG regions (insula, pars opercularis, and triangularis), inferior parietal lobule (IPL), and STG has been found to be more strongly connected in bilinguals compared with monolinguals (García-Pentón et al., 2014). However, the exact language processes that are facilitated by this circuit in L2 learning remain unclear. Some evidence suggests that these regions support L2 word learning and lexical retrieval. For example, the WM microstructure of the left arcuate fasciculus, which connects the left IFG with left IPL and STG, has been associated with novel word learning (López-Barroso et al., 2013). Yang et al. (2015) showed that successful compared with less successful learners of novel words had stronger connectivity within the left IFG-IPL-STG circuit during a word-picture association task. Gray matter density of the left IFG was corrected positively with L2 lexical efficiency, measured by the number of words produced in a timed verbal fluency task, whereas gray matter density of the supramarginal gyrus reflected the number of words known (Grogan et al., 2012). Our measure of lexical retrieval during timed spontaneous speech is similar to the lexical efficiency measure by Grogan et al. Consistent with these results, we show greater connectivity between the left AI/FO and left pSTG in participants whose lexical retrieval abilities improved more after intensive language training.

However, other evidence suggests the left IFG-parietal-STG circuit also supports phonological processing. Successful learning of non-native sounds has been associated with activations in left STG and AI/FO and IFG (Golestani and Zatorre, 2004) and with stronger left $\mathrm{AI} / \mathrm{FO}-$ superior parietal connectivity during rest (Ventura-Campos et al., 2013). Wong et al. (2007) showed successful learning of pitch patterns in words was associated with activations of the left pSTG. Thus, it is possible that the pathway connecting the left IFG and STG plays a role in semantic and phonological processes, both of which facilitate L2 learning. 
There is still debate regarding the exact role of the left pSTG in language processes. According to one model, the left pSTG, along with left IPL and left frontal speech articulatory regions, form the "dorsal stream" for mapping phonological representations into articulatory representations in speech production (Hickok and Poeppel, 2007). Another model suggests that the left pSTG is also involved in lexical-semantic processing (Friederici et al., 2009; Friederici, 2012). Our results do not answer this question but extend previous findings by showing that pretraining intrinsic functional connectivity can be related to L2 learning success and suggest that interactions of the left IFG and pSTG may facilitate processes that are important for lexical retrieval in L2 learning.

We also observed a correlation between improvement in L2 lexical retrieval and resting-state functional connectivity between the left AI/FO and dorsal ACC. The dorsal ACC, together with the anterior insula, form the core of the salience network (Seeley et al., 2007), which is involved in control processes that detect salient stimuli and switch between internal and external attention to guide behavior (Menon and Uddin, 2010). The functional coupling of the AI/FO and dorsal ACC enables bottom-up attention switching and top-down monitoring and selecting of sensory input (Menon and Uddin, 2010). Word retrieval and planning during speech require such domain-general control functions (Roelofs and Piai, 2011). Our results suggest that stronger functional coupling between the left AI/FO and dorsal ACC may reflect better salience processing, which contributes to greater improvement in lexical fluency in L2 learning.

In contrast to the AI/FO-pSTG profiles correlating with improvement in lexical retrieval, a different connectivity pattern correlated with improved L2 reading speed. Reading abilities have been associated previously with variability in resting-state connectivity (Koyama et al., 2011; Zhang et al., 2014). Zhang et al. (2014) reported that higher connectivity between visual and phonological processing regions corresponded with faster singleword reading. Anatomically, the VWFA is connected preferentially to the left perisylvian STG and left IFG. This contrasts with a nearby functional region, the fusiform face area, that is related specifically to face processing (Bouhali et al., 2014). The WM integrity of the posterior part of the arcuate fasciculus (Catani et al., 2005), which connects parietal and temporal language regions, including the VWFA, IPL, and STG, has been shown to correlate with L1 reading performance (Thiebaut de Schotten et al., 2014). The acquisition of literacy is thought to strengthen the functional and anatomical link between phonemic and graphemic representations of language (Dehaene et al., 2015). Our results show that variability in intrinsic functional connectivity between VWFA and left mid-STG can account for individual differences in acquiring reading skills in L2. A previous study suggests that the mid-portion of the left STG supports sentencelevel semantic processing (Friederici et al., 2003), which is necessarily involved in reading and facilitates rapid reading for meaning. It is possible that stronger coupling between the VWFA and left mid-STG reflects more efficient mapping of visual input of written words to phonological and semantic representations during reading, which may benefit both L1 and L2 learning.

This study focused on speech samples rather than standardized tests because participants were not trained in a laboratory but underwent language training in a naturalistic languagelearning environment. Using language samples, we assessed improvement in communicative exchanges and reading competence, both necessary for developing proficiency in an L2. Our results are consistent with previous studies using standardized measures but extend these to more ecologically valid tasks. We focused on two aspects of the speech sample most relevant to assessing distinctions between improvement in spontaneous speech (learning and retrieval of novel words) and improvement in reading (reading speed in L2). Additional pathways are likely to be important when other aspects of language are investigated, such as articulatory proficiency/accent and grammatical expertise.

Moreover, our study did not assess how L1 skills are related to performance in L2 learning because of homogeneity in L1 skills across participants and across time points assessed. It is possible that acquisition of $\mathrm{L} 1$ shapes and strengthens connections in the brain that support L2 learning. Another possibility is that variability in functional connectivity of the language network exists from birth, which later contributes to individual differences in $\mathrm{L} 2$ learning during adulthood regardless of differences in L1 acquisition. Future studies are needed to test whether optimal brain organization for L1 acquisition also leads to better outcomes for L2 learning during adulthood.

\section{References}

Ardila A, Bernal B, Rosselli M (2014) Participation of the insula in language revisited: a meta-analytic connectivity study. J Neurolinguistics 29:31-41. CrossRef

Baldassarre A, Lewis CM, Committeri G, Snyder AZ, Romani GL, Corbetta M (2012) Individual variability in functional connectivity predicts performance of a perceptual task. Proc Natl Acad Sci U S A 109:3516-3521. CrossRef Medline

Baldo JV, Schwartz S, Wilkins D, Dronkers NF (2006) Role of frontal versus temporal cortex in verbal fluency as revealed by voxel-based lesion symptom mapping. J Int Neuropsychol Soc 12:896-900. Medline

Behzadi Y, Restom K, Liau J, Liu TT (2007) A component based noise correction method (CompCor) for BOLD and perfusion based fMRI. Neuroimage 37:90-101. CrossRef Medline

Benton AL (1968) Differential behavioral effects in frontal lobe disease. Neuropsychologia 6:53-60. CrossRef

Berken JA, Gracco VL, Chen JK, Watkins KE, Baum S, Callahan M, Klein D (2015) Neural activation in speech production and reading aloud in native and non-native languages. Neuroimage 112:208-217. CrossRef Medline

Biesbroek JM, van Zandvoort MJ, Kappelle LJ, Velthuis BK, Biessels GJ, Postma A (2015) Shared and distinct anatomical correlates of semantic and phonemic fluency revealed by lesion-symptom mapping in patients with ischemic stroke. Brain Struct Funct. Advance online publication. Retrieved December 9, 2015. doi: 10.1007/s00429-015-1033-8. CrossRef Medline

Bird J, Bishop DV, Freeman NH (1995) Phonological awareness and literacy development in children with expressive phonological impairments. J Speech Hear Res 38:446-462. CrossRef Medline

Bouhali F, Thiebaut de Schotten M, Pinel P, Poupon C, Mangin JF, Dehaene S, Cohen L (2014) Anatomical connections of the visual word form area. J Neurosci 34:15402-15414. CrossRef Medline

Catani M, Jones DK, ffytche DH (2005) Perisylvian language networks of the human brain. Ann Neurol 57:8-16. CrossRef Medline

Chai XJ, Castañón AN, Ongür D, Whitfield-Gabrieli S (2012) Anticorrelations in resting state networks without global signal regression. Neuroimage 59:1420-1428. CrossRef Medline

Chee MW, Soon CS, Lee HL, Pallier C (2004) Left insula activation: a marker for language attainment in bilinguals. Proc Natl Acad Sci U S A 101:15265-15270. CrossRef Medline

Dahl A, Vulchanova MD (2014) Naturalistic acquisition in an early language classroom. Front Psychol 5:329. CrossRef Medline

Damasio H, Tranel D, Grabowski T, Adolphs R, Damasio A (2004) Neural systems behind word and concept retrieval. Cognition 92:179-229. CrossRef Medline

Dehaene S, Cohen L (2011) The unique role of the visual word form area in reading. Trends Cogn Sci 15:254-262. CrossRef Medline

Dehaene S, Pegado F, Braga LW, Ventura P, Nunes Filho G, Jobert A, Dehaene-Lambertz G, Kolinsky R, Morais J, Cohen L (2010) How learning to read changes the cortical networks for vision and language. Science 330:1359-1364. CrossRef Medline 
Dehaene S, Cohen L, Morais J, Kolinsky R (2015) Illiterate to literate: behavioural and cerebral changes induced by reading acquisition. Nat Rev Neurosci 16:234-244. CrossRef Medline

Dunn LM, Dunn LM (1997) Peabody Picture Vocabulary Test-III. Circle Pines, MN: American Guidance Service.

Fox MD, Raichle ME (2007) Spontaneous fluctuations in brain activity observed with functional magnetic resonance imaging. Nat Rev Neurosci 8:700-711. CrossRef Medline

Fox MD, Snyder AZ, Vincent JL, Raichle ME (2007) Intrinsic fluctuations within cortical systems account for intertrial variability in human behavior. Neuron 56:171-184. CrossRef Medline

Friederici AD (2012) The cortical language circuit: From auditory perception to sentence comprehension. Trends Cogn Sci 16:262-268. CrossRef Medline

Friederici AD, Rüschemeyer SA, Hahne A, Fiebach CJ (2003) The role of left inferior frontal and superior temporal cortex in sentence comprehension: localizing syntactic and semantic processes. Cereb Cortex 13:170-177. CrossRef Medline

Friederici AD, Makuuchi M, Bahlmann J (2009) The role of the posterior superior temporal cortex in sentence comprehension. Neuroreport 20: 563-568. CrossRef Medline

Gaillard R, Naccache L, Pinel P, Clémenceau S, Volle E, Hasboun D, Dupont S, Baulac M, Dehaene S, Adam C, Cohen L (2006) Direct intracranial, fMRI, and lesion evidence for the causal role of left inferotemporal cortex in reading. Neuron 50:191-204. CrossRef Medline

García-Pentón L, Pérez Fernández A, Iturria-Medina Y, Gillon-Dowens M, Carreiras M (2014) Anatomical connectivity changes in the bilingual brain. Neuroimage 84:495-504. CrossRef Medline

Gaser C, Schlaug G (2003) Brain structures differ between musicians and non-musicians. J Neurosci 23:9240-9245. Medline

Goldrick M, Blumstein SE (2006) Cascading activation from phonological planning to articulatory processes: evidence from tongue twisters. Lang Cogn Process 21:649-683. CrossRef

Golestani N, Zatorre RJ (2004) Learning new sounds of speech: Reallocation of neural substrates. Neuroimage 21:494-506. CrossRef Medline

Golestani N, Zatorre RJ (2009) Individual differences in the acquisition of second language phonology. Brain Lang 109:55-67. CrossRef Medline

Grogan A, Parker Jones O, Ali N, Crinion J, Orabona S, Mechias ML, Ramsden S, Green DW, Price CJ (2012) Structural correlates for lexical efficiency and number of languages in non-native speakers of English. Neuropsychologia 50:1347-1352. CrossRef Medline

Heisler L, Goffman L, Younger B (2010) Lexical and articulatory interactions in children's language production. Dev Sci 13:722-730. CrossRef Medline

Hickok G, Poeppel D (2007) The cortical organization of speech processing. Nat Rev Neurosci 8:393-402. CrossRef Medline

Hirshorn EA, Thompson-Schill SL (2006) Role of the left inferior frontal gyrus in covert word retrieval: neural correlates of switching during verbal fluency. Neuropsychologia 44:2547-2557. CrossRef Medline

Homae F, Hashimoto R, Nakajima K, Miyashita Y, Sakai KL (2002) From perception to sentence comprehension: the convergence of auditory and visual information of language in the left inferior frontal cortex. Neuroimage 16:883-900. CrossRef Medline

Kircher TT, Brammer MJ, Williams SC, McGuire PK (2000) Lexical retrieval during fluent speech production: an fMRI study. Neuroreport 11: 4093-4096. CrossRef Medline

Klein D, Milner B, Zatorre RJ, Meyer E, Evans AC (1995) The neural substrates underlying word generation: a bilingual functional-imaging study. Proc Natl Acad Sci U S A 92:2899-2903. CrossRef Medline

Koyama MS, Di Martino A, Zuo XN, Kelly C, Mennes M, Jutagir DR, Castellanos FX, Milham MP (2011) Resting-state functional connectivity indexes reading competence in children and adults. J Neurosci 31:86178624. CrossRef Medline

Lewis BA, Freebairn L (1992) Residual effects of preschool phonology disorders in grade school, adolescence, and adulthood. J Speech Hear Res 35:819-831. CrossRef Medline

López-Barroso D, Catani M, Ripollés P, Dell'Acqua F, Rodríguez-Fornells A, de Diego-Balaguer R (2013) Word learning is mediated by the left arcuate fasciculus. Proc Natl Acad Sci U S A 110:13168-13173. CrossRef Medline

Marian V, Blumenfeld HK, Kaushanskaya M (2007) The language experience and proficiency questionnaire (LEAP-Q): assessing language profiles in bilinguals and multilinguals. J Speech Lang Hear Res 50:940-967. CrossRef Medline

McCandliss BD, Cohen L, Dehaene S (2003) The visual word form area: expertise for reading in the fusiform gyrus. Trends Cogn Sci 7:293-299. CrossRef Medline

Menon V, Uddin LQ (2010) Saliency, switching, attention and control: a network model of insula function. Brain Struct Funct 214:655-667. CrossRef Medline

Milner B (1964) Some effects of frontal lobectomy in man. In: The frontal granular cortex and behavior, pp 313-334. New York: McGraw-Hill.

Nakamura K, Kuo WJ, Pegado F, Cohen L, Tzeng OJ, Dehaene S (2012) Universal brain systems for recognizing word shapes and handwriting gestures during reading. Proc Natl Acad Sci U S A 109:20762-20767. CrossRef Medline

Nestor PJ, Graham NL, Fryer TD, Williams GB, Patterson K, Hodges JR (2003) Progressive non-fluent aphasia is associated with hypometabolism centred on the left anterior insula. Brain 126:2406-2418. CrossRef Medline

Perani D, Abutalebi J, Paulesu E, Brambati S, Scifo P, Cappa SF, Fazio F (2003) The role of age of acquisition and language usage in early, highproficient bilinguals: an fMRI study during verbal fluency. Hum Brain Mapp 19:170-182. CrossRef Medline

Price CJ (2012) A review and synthesis of the first 20 years of PET and fMRI studies of heard speech, spoken language and reading. Neuroimage 62: 816-847. CrossRef Medline

Raboyeau G, Marie N, Balduyck S, Gros H, Démonet JF, Cardebat D (2004) Lexical learning of the English language: a PET study in healthy French subjects. Neuroimage 22:1808-1818. CrossRef Medline

Roehrich-Gascon D, Small SL, Tremblay P (2015) Structural correlates of spoken language abilities: a surface-based region-of interest morphometry study. Brain Lang 149:46-54. CrossRef Medline

Roelofs A, Piai V (2011) Attention demands of spoken word planning: a review. Front Psychol 2:307. CrossRef Medline

Schön D, Magne C, Besson M (2004) The music of speech: music training facilitates pitch processing in both music and language. Psychophysiology 41:341-349. CrossRef Medline

Seeley WW, Menon V, Schatzberg AF, Keller J, Glover GH, Kenna H, Reiss AL, Greicius MD (2007) Dissociable intrinsic connectivity networks for salience processing and executive control. J Neurosci 27:2349-2356. CrossRef Medline

Thiebaut de Schotten M, Cohen L, Amemiya E, Braga LW, Dehaene S (2014) Learning to read improves the structure of the arcuate fasciculus. Cereb Cortex 24:989-995. CrossRef Medline

Thurstone LL, Thurstone TG (1943) The Chicago tests of primary mental abilities. Chicago: Science Research Associates.

Tomasi D, Volkow ND (2012) Resting functional connectivity of language networks: characterization and reproducibility. Mol Psychiatry 17: 841-854. CrossRef Medline

Troiani V, Fernández-Seara MA, Wang Z, Detre JA, Ash S, Grossman M (2008) Narrative speech production: an fMRI study using continuous arterial spin labeling. Neuroimage 40:932-939. CrossRef Medline

Ventura-Campos N, Sanjuán A, González J, Palomar-García MÁ, RodríguezPujadas A, Sebastián-Gallés N, Deco G, Ávila C (2013) Spontaneous brain activity predicts learning ability of foreign sounds. J Neurosci 33 : 9295-9305. CrossRef Medline

Veroude K, Norris DG, Shumskaya E, Gullberg M, Indefrey P (2010) Functional connectivity between brain regions involved in learning words of a new language. Brain Lang 113:21-27. CrossRef Medline

Wagner AD, Paré-Blagoev EJ, Clark J, Poldrack RA (2001) Recovering meaning: left prefrontal cortex guides controlled semantic retrieval. Neuron 31:329-338. CrossRef Medline

Wei T, Liang X, He Y, Zang Y, Han Z, Caramazza A, Bi Y (2012) Predicting conceptual processing capacity from spontaneous neuronal activity of the left middle temporal gyrus. J Neurosci 32:481-489. CrossRef Medline

Whitfield-Gabrieli S, Nieto-Castanon A (2012) Conn: a functional connectivity toolbox for correlated and anticorrelated brain networks. Brain Connect 2:125-141. CrossRef Medline

Wong PC, Perrachione TK, Parrish TB (2007) Neural characteristics of successful and less successful speech and word learning in adults. Hum Brain Mapp 28:995-1006. CrossRef Medline

Yang J, Gates KM, Molenaar P, Li P (2015) Neural changes underlying successful second language word learning: an fMRI study. J Neurolinguistics 33:29-49. CrossRef

Zhang M, Li J, Chen C, Xue G, Lu Z, Mei L, Xue H, Xue F, He Q, Chen C, Wei M, Dong Q (2014) Resting-state functional connectivity and reading abilities in first and second languages. Neuroimage 84:546-553. CrossRef Medline 